\title{
FONDAMENTO PLASTICO DELLA SCULTURA E PITTURA FUTURISTE
}

\author{
Umberto Boccioni \\ Tradução de Rafael Zamperetti Copetti
}

Com a publicação de "Fundamento plástico da escultura e da pintura futurista”, em língua portuguesa, damos continuidade à iniciativa que inauguramos no número 29 da UniLetras: oferecer ao leitor uma pequena amostra do primo novecento italiano através da publicação de textos representativos, desse período da cultura italiana, cuja acessibilidade em nossa língua não seja de todo simples. A exemplo do que ocorreu no número anterior da revista, agora novamente apresentamos um outro texto do artista plástico e teórico do Futurismo Italiano Umberto Boccioni.

Boccioni, um dos mais atuantes membros desse movimento da vanguarda histórica européia, cujo manifesto de fundação por sinal completará cem anos em fevereiro de 2009, desenvolve em inúmeras conferências e artigos que faz circular em importantes revistas culturais da época diversos conceitos fundamentais para as suas teorias e práxis pictórica e escultórica, entre eles o de linhas-força e o de transcendentalismo físico. Algumas dessas propostas serão posteriormente retomadas, e, em 1914, organicamente coligidas no livro Pittura e scultura futurista: dinamismo plástico (Pintura e escultura futurista: dinamismo plástico), cuja publicação no Brasil é prevista para 2009.

Além dessas preocupações, no texto que ora disponibilizamos ao leitor, já figuram esboçados outros temas caros aos artistas e escritores futuristas e que de igual forma permeiam o referido livro. Entre eles, destacamos a reflexão acerca do papel que caberia ao Futurismo na destruição da tradição italiana e o intuito por parte dos intelectuais vinculados ao movimento de elucidar as leis que se configuravam no período, a partir do surgimento de uma nova sensibilidade renovada pelos valores do novo mundo que estaria em consti-

*Universidade Federal de Santa Catarina/ CAPES - Università degli Studi di Padova/ Itália.

Uniletras, Ponta Grossa, v. 30, n. 2, p. 469-478, jul./dez. 2008 Disponível em <http://www.uepg.br/uniletras $>$ 
tuição. Quanto à primeira questão, é patente a contraposição com a situação francesa, de todo diversa daquela italiana, como se percebe quando o artista discorre a respeito da responsabilidade futurista no que concerne à realização, em poucos anos, em seu país, daquilo que na França resultaria do esforço de várias gerações. Ademais, a interação com os intelectuais franceses ocorre também quando da polêmica com Gauguin, os impressionistas e os cubistas. Sobre isso, cabe mencionar que a participação dos futuristas no debate literário e cultural franco-italiano dos anos que imediatamente antecederam à I Grande Guerra é verdadeiramente produtiva e operante.

De igual modo, preocupação fundamental na poética boccioniana, e que se faz presente também no texto que aqui apresentamos, é a problemática relativa ao conceito de movimento em pintura e em escultura. Isto é, a problemática atinente aos movimentos relativo e absoluto dos objetos, a qual se encontra intimamente atrelada à questão do dinamismo plástico. Escreve Boccioni: "Aquilo que nós queremos dar é o objeto vivido no seu devir dinâmico, isto é, dar a síntese das transformações que o objeto sofre nos seus dois movimentos, relativo e absoluto. Nós queremos dar o estilo do movimento. Nós não queremos observar, dissecar e transpor em imagens; nós nos identificamos na coisa, o que é profundamente diferente".

Assim, deixamos agora o leitor com "Fundamento plástico da escultura e da pintura futurista”, publicado na revista florentina Lacerba, em março de 1913.

\section{5 marzo 1913}

Il nostro idealismo costruttivo toglie le sue leggi dalle nuove certezze dateci dalla scienza.

Esso vive di puri elementi plastici ed è illuminato dall'intuizione di una ultrasensibilità sòrta con le nuovissime condizioni di vita createci dalle scoperte scientifiche.

Il nostro compito è quello di distruggere quattro secoli di tradizione italiana. Immettere nel vuoto che ne può risultare tutti i germi di potenza che sono negli esempi dei primitivi, dei barbari d'ogni paese e nei rudimenti di nuovissima sensibilità che appaiono in tutte le manifestazioni antiartistiche della nostra epoca; cafè-chantant, grammofono, cinematografo, affichesluminose architettura meccanica, vita notturna, vita delle pietre e dei cristalli, 
occultismo, magnetismo, velocità ecc. Superare la crisi di rudimentale di grottesco o mostruoso che è segno di forza senza legge. Scoprire le leggi che stanno fromandosi nella nostra sensibilità rinnovata ed entrare in un nuovo mondo di valori definitivi.

La cultura dei nostri avversari risale sempre ad epoche più o meno recenti per trovare esempi contrari alla nostra concezione pittorica futurista.

Quanto più si risale nelle epoche anteriori tanto meno si trova l'ossessione miserevole dell'inganno ottico che sembra una delle armi più forti e più usate per combatterci.

La pittura e la scultura nelle epoche primordiali si preoccupano di suggestionare e suggerire e lo fanno con qualsiasi mezzo senza il più lontano accenno alla stupida esercitazione artistica. In quest'epoche felici non si conosce la parola arte e non si conoscono le artificiose suddivisioni di pittura, scultura, musica, letteratura, filosofia, poesia ... Tutto invece è architettura perché tutto in arte deve essere creazione di organismi autonomi costruiti con i valori astratti della realtà. Ecco perché noi siamo recisamente e violentemente antiartistici, antipittorici, antiscultorii, antipoetici, antimusicali. Le opere d'arte dei selvaggi così fatalmente entrate nel processo di rinnovazione moderna provano la verità di quanto affermo.

Il viaggio a Taiti di Gauguin, la comparsa degli idoli e dei feticci del Centro-Affrica negli ateliers dei nostri amici di Montmartre sono una fatalità storica nel campo della sensibilità europea, come nell'organismo di un popolo in decadenza l'invasione di una razza barbara!

Noi italiani abbiamo bisogno del barbaro per rinnovarci. La nostra razza ha sempre dominato e si è sempre rinnovata coi contatti barbarici. Noi dobbiamo sconquassare, atterrare e distruggere la nostra tradizionale armonia che ci fa cadere in un "graziozo » materiato di vergognosi lenocini sentimentali. Noi neghiamo il passato perché vogliamo dimenticare e dimenticare in arte vuol dire rinnovarsi.

Questo violento sforzo di rinnovazione lo abbiamo fatto in noi in pochi anni mentre in Francia vi hanno cooperato gli sforzi di intere generazioni! Quello che noi vogliamo proclamare ed imporre in Italia è la nuova sensibilità che dà alla pittura e alla scultura e a tutte le arti un nuovo materiale per creare nuove relazioni di forme e di colori. Tutto questo materiale d'espressione è assolutamente oggettivo e non si può rinnovare se non liberandolo dai supervalori che l'arte e la coltura tradizionale gli hanno appiccicato sopra. 
Bisogna dimenticare quello che finora si è chiesto al quadro e alla statua. Bisogna considerare l'opera d'arte pittorica o scultorica come costruzioni di una nuova realtà interna che gli elementi della realtà esterna concorrono a costruire per una legge di analogia plastica quasi completamente sconosciuta prima di noi. Ed è per questa analogia, essenza stessa della poesia, che noi perverremo agli stati d'animo plastici.

Quando per la scultura dico che bisogna modellare l'atmosfera intendo dire che sopprimo cioè dimentico il valore sentimentale e tradizionale dell'atmosfera l'ultimo verismo vela le cose, le fa diafane, lontane, quasi un sogno ecc. ecc. ma considero quest'atmosfera come una materialità che vive tra oggetto e oggetto, ne varia il valore plastico, e invece di sorvolarvi sopra come un soffio perché la cultura mi ha appreso che l'atmosfera è gassosa impalpabile ecc. ecc. io la sento, la cerco, l'afferro, l'accentuo, nelle variazioni che le imprimono le luci, le ombre e le correnti delle forze dei corpi. Quindi io creo l'atmosfera.

Quando, attraverso le opere, si capirà questa verità della scultura futurista, si vedrà la forma dell'atmosfera dove prima si vedeva il vuoto e poi con gl'impressionisti una nebbia. Questa nebbia era già un primo passo verso la plastica atmosferica, verso il nostro trascendentalismo fisico che è poi un altro passo verso la percezione di analoghi fenomeni fin'ora occulti alla nostra sensibilità ottusa, quali le percezioni dell'emanazioni luminose del nostro corpo di cui parlai nella mia prima conferenza a Roma e che la lastra fotografica già riproduce.

Ora questa misurazione sensibile di ciò che sembra un vuoto; questa sovrapposizione sensibile di strati su quelle che chiamiamo cose e su le forme che le determinano, questo nuovo aspetto della realtà è una delle basi della nostra pittura e della nostra scultura. Si chiarisce quindi perché dal nostro oggetto, partono linee o correnti infinite che lo fanno vivere nell'ambiente creato dalle sue vibrazioni.

Perché le distanze tra un oggetto e l'altro non sono degli spazi vuoti ma delle continuità di materia di diversa intensità, che noi riveliamo con linee sensibili che non corrispondono alla verità fotografica. Ecco perché nei nostri quadri non abbiamo l'oggetto e il vuoto, ma solo una maggiore o minore intensità e solidità di spazi.

È chiarissimo con ciò quello che ho chiamato solidificazione dell’impressionismo. 
Questa misurazione degli oggetti e delle forme atmosferiche che essi creano e che li avvolgono, forma il valore QUANTITATIVO dell'oggetto. Se poi saliamo ancora nella percezione e traduciamo l'altro valore, cioè il valore QUALITATIVO noi avremo il MOTO dell'oggetto. Moto è qualità, e di conseguenza qualità equivale a sentimento per la nostra plastica.

L’accusa di cinematografia ci fa ridere come una volgare imbecillità. Noi non suddividiamo delle immagini visuali, noi ricerchiamo un segno, o meglio, una forma unica che sostituisca al vecchio concetto di divisione, il nuovo concetto di continuità.

Ogni suddivisione di moto è un fatto completamente arbitrario, come è completamente arbitraria ogni suddivisione di materia. Henry Bergson dice: Tuote division de la matière en corps indépendants aux contours absolument determinés est une division artificielle. E altrove: Tout mouvement en tant que passage d'un répos à un répos est absolument indivisible.

Abbiamo noi trovato una formula che dia la continuità nello spazio? Le formule in arte le hanno date i capolavori, e con essi i periodi evolutivi si son chiusi...; cosa possiamo sinceramente rispondere noi con i nostri quadri che hanno mesi di vita? Noi siamo nel campo della ricerca e nessun terreno è più felice per questa ricerca dell'inebbriante novità della vita moderna.

Quindi malgrado la nostra violenta aspirazione verso il definitivo, noi neghiamo oggi, allo stadio in cui si trova la nostra sensibilità, la possibilità d'un cifrario astratto, d'una specie di concettualismo plastico che possa nella sua determinazione tipica sostituire praticamente l'intuizione dell'individuo.

Il passare in arte al concetto quando manca in noi l'identità tra la realtà esterna e l'interna è pericolosissimo, e la gelida fabbricazione d'immagini di alcuni cubisti lo dimostra.

S'ingannerebbe quindi chi approvando in teoria alcune delle nostre affermazioni su una nuova traduzione plastica della realtà, cercasse poi un'emozione nelle nostre tele secondo le vecchie abitudini mentali.

Quello che non si deve dimenticare è questo: il punto di vista, nell'arte futurista, è completamente cambiato.

Per quanto interiore, la pittura moderna è sempre stata fino ad oggi uno spettacolo di immagini che si svolgono davanti a noi. Per quanto nei cubisti l'oggetto sia visto nella sua complessità, e il quadro sia costituito dall'armonica 
combinazione di una o più complessità in una complessità-ambiente, lo spettacolo non cambia.

Quello che noi vogliamo dare è l'oggetto vissuto nel suo divenire dinamico, cioè dare la sintesi delle trasformazioni che l'oggetto subisce nei suoi due moti, relativo ed assoluto.

Noi vogliamo dare lo stile del movimento. Noi non vogliamo osservare, dissecare e trasportare in immagini; noi ci identifichiamo nella cosa, il che è profondamente diverso.

Quindi per noi l'oggetto non ha una forma a priori, ma sola è definibile la linea che segna la relazione tra il suo peso (quantità) e la sua espansione (qualità).

Questo ci suggerisce le linee-forze che caratterizzano l'oggetto e ci portano ad una unità che è l'interpretazione essenziale dell'oggetto, cioè l'intuizione della vita. La nostra è una ricerca del definitivo nella successione di stati di intuizione.

Rifiutare una realtà a priori, ecco l'abisso che ci divide dal Cubismo, che fa di noi futuristi la punta estrema della pittura mondiale. In Italia, noi siamo i primi artisti che si preoccupino di dare alla loro arte quello che fu sempre carattere dell'arte italiana nei suoi periodi migliori: stile e realtà.

\title{
FUNDAMENTO PLÁSTICO DA ESCULTURA E DA PINTURA FUTURISTA
}

\author{
Tradução de Rafael Zamperetti Copetti
}

15 de março de 1913

O nosso idealismo construtivo colhe as suas leis nas novas certezas oferecidas pela ciência.

Ele se nutre de puros elementos plásticos e é iluminado pela intuição de uma ultrasensibilidade surgida com as novíssimas condições de vida criadas pelas descobertas científicas. 
A nossa tarefa é destruir quatro séculos de tradição italiana. Introduzir no vazio daí decorrente todos os germes de potência contidos nos exemplos dos primitivos, dos bárbaros de todos os países e nos rudimentos de novíssima sensibilidade, que surgem em todas as manifestações anti-artísticas da nossa época; café-concerto, gramofone, cinematógrafo, cartazes-luminosos, arquitetura mecânica, vida noturna, vida das pedras e dos cristais, ocultismo, magnetismo, velocidade etc. Superar a crise de incipiência, de grotesco ou monstruoso que é indício de força sem lei. Descobrir as leis que estão se formando na nossa sensibilidade renovada e entrar em um novo mundo de valores definitivos.

A cultura dos nossos adversários se refere sempre a épocas mais ou menos recentes para encontrar exemplos contrários à nossa concepção pictórica futurista.

Quanto mais se volta a épocas passadas, menos se encontra a obsessão miserável do engano ótico que parece uma das armas mais fortes e mais utilizadas para nos combater.

A pintura e a escultura nos períodos primeiros se preocupam em estimular e sugerir e o fazem com qualquer meio sem a mais longínqua alusão ao estúpido exercício artístico. Nestas épocas felizes, não se conhece a palavra arte e não se conhecem as artificiosas subdivisões entre pintura, escultura, música, literatura, filosofia, poesia.... Tudo, no entanto, é arquitetura porque tudo em arte deve ser criação de organismos autônomos construídos com os valores abstratos da realidade. Eis porque nós somos terminante e violentamente antiartísticos, antipictóricos, anti-escultóricos, anti-poéticos, anti-musicais. As obras de arte dos selvagens assim fatalmente introduzidas no processo de renovação moderna comprovam a verdade do que afirmo.

A viagem de Gauguin ao Taiti, o surgimento dos ídolos e dos feitiços da África Central nos ateliers dos nossos amigos de Montmartre são uma fatalidade histórica no campo da sensibilidade européia, como na estrutura de um povo em decadência diante da invasão de uma raça bárbara!

Nós, italianos, precisamos do bárbaro para nos renovarmos. A nossa raça sempre dominou e sempre se renovou através dos contatos com os bárbaros. Nós devemos abalar, prostrar e destruir a nossa harmonia tradicional, que nos faz cair em uma “amável” materialização de vergonhosos lenocínios sentimentais. Nós negamos o passado porque queremos esquecer e esquecer em arte quer dizer renovar-se. 
Fizemos este violento esforço de renovação em poucos anos enquanto, na França, colaboraram os esforços de gerações inteiras! Aquilo que nós queremos proclamar e impor à Itália é a nova sensibilidade que dá à pintura e à escultura e a todas as artes um novo material para criar novas relações de formas e cores. Todo esse material de expressão é absolutamente objetivo e não se pode lhe renovar se não o liberando dos supervalores que a arte e a cultura tradicionais lhe impingiram.

É preciso esquecer aquilo que até agora se exigiu do quadro e da estátua. É preciso considerar a obra de arte pictórica ou escultórica como construções de uma nova realidade interna em que os elementos da realidade externa concorrem para construir através de uma lei de analogia plástica quase completamente desconhecida anteriormente a nós. E é por esta analogia, essência mesma da poesia, que nós tomamos a dianteira quanto aos estados de ânimo plásticos.

Quando afirmo, em relação à escultura, que é preciso modelar a atmosfera, quero dizer que anulo, isto é, esqueço o valor sentimental e tradicional da atmosfera, do último verismo, que oculta as coisas, as faz diáfanas, longínquas, quase um sonho etc. etc., mas considero esta atmosfera uma materialidade que existe entre objeto e objeto, que diversifica o valor plástico, em vez de passarlhes por cima como um sopro porque a cultura me ensinou que a atmosfera é gasosa impalpável etc. etc., eu tento senti-la, procurá-la, agarrá-la e enfatizá-la, nas variações que lhe imprimem as luzes, as sombras e as correntes das forças dos corpos. Logo, eu crio a atmosfera.

Quando, através das obras, se compreender esta verdade da escultura futurista, ver-se-á a forma da atmosfera onde primeiro se via o vazio e depois, com os impressionistas, uma névoa. Essa névoa era já um primeiro passo em direção à plástica atmosférica, em direção ao nosso transcendentalismo físico que é, pois, um outro passo em direção à percepção de fenômenos análogos até agora ocultos para a nossa sensibilidade obtusa, que as percepções das emanações luminosas do nosso corpo, das quais falei na minha primeira conferência em Roma, e que a lâmina fotográfica já reproduz.

Ora, esta mensuração sensível daquilo que parece um vazio; esta sobreposição sensível de estratos sobre o que chamamos coisas e sobre as formas que as determinam, este novo aspecto da realidade é uma das bases da nossa pintura e da nossa escultura. Explica-se, então, porque do nosso objeto partem linhas ou correntes infinitas que o fazem viver no ambiente criado pelas suas vibrações. 
Porque as distâncias entre um objeto e outro não são os espaços vazios, mas as continuidades de matéria de diferente intensidade, que nós revelamos com linhas sensíveis que não correspondem à verdade fotográfica. Eis porque nos nossos quadros não temos o objeto e o vazio, mas apenas uma maior ou menor intensidade e solidez dos espaços.

É evidente com isso o que chamei solidificação do impressionismo.

Esta mensuração dos objetos e das formas atmosféricas que esses criam e que os envolvem forma o valor QUANTITATIVO do objeto. Se, em seguida, avançamos ainda na percepção e traduzimos o outro valor, isto é, o valor QUALITATIVO, nós teremos o MOVIMENTO do objeto. Movimento é qualidade e, conseqüentemente, qualidade equivale a sentimento para a nossa plástica.

A acusação de cinematografia nos faz rir como uma vulgar estupidez. Nós não subdividimos as imagens visuais, nós pesquisamos um signo, ou melhor, uma forma única que substitua o velho conceito de divisão pelo novo conceito de continuidade.

Toda subdivisão de movimento é um fato completamente arbitrário, como é completamente arbitrária toda subdivisão da matéria. Henry Bergson diz: Toute division de la matière en corps indépendants aux contours absolument determinés est une division artificielle. E em outro lugar: Tout mouvement en tant que passage d'un répos à un répos est absolument indivisible.

Teremos nós encontrado uma fórmula que dê a continuidade no espaço? As fórmulas em arte foram dadas pelas obras-primas, e com elas os períodos evolutivos se encerraram...; o que sinceramente podemos responder com os nossos quadros que têm meses de vida? Nós estamos no campo da pesquisa e nenhum terreno é mais propício para esta pesquisa do que a inebriante novidade da vida moderna.

Assim, a despeito da nossa violenta aspiração em direção ao definitivo, nós negamos hoje, no estado em que se encontra a nossa sensibilidade, a possibilidade de uma contracifra abstrata, de uma espécie de conceitualismo plástico que possa, na sua determinação típica, substituir praticamente a intuição do indivíduo.

Em arte, a passagem ao conceito, quando falta em nós a identidade entre a realidade externa e a interna, é perigosíssima, e a gélida fabricação de imagens de alguns cubistas o demonstra. 
Trair-se-ia, pois, quem, aprovando em teoria algumas das nossas afirmações sobre uma nova tradução plástica da realidade, buscasse em seguida uma emoção nas nossas telas segundo os velhos hábitos mentais.

Aquilo que não se deve esquecer é isto: o ponto de vista, na arte futurista, é completamente diferenciado.

Porquanto interior, a pintura moderna sempre foi até hoje um espetáculo de imagens que se desenvolvem diante de nós. Uma vez que nos cubistas o objeto é visto na sua complexidade, e o quadro é constituído pela harmônica combinação de uma ou mais complexidades em uma complexidade-ambiente, o espetáculo não muda.

Aquilo que nós queremos dar é o objeto vivido no seu devir dinâmico, isto é, dar a síntese das transformações que o objeto sofre nos seus dois movimentos, relativo e absoluto.

Nós queremos dar o estilo do movimento. Nós não queremos observar, dissecar e transpor em imagens; nós nos identificamos na coisa, o que é profundamente diferente.

Assim, para nós o objeto não possui uma forma a priori, mas apenas é definível a linha que assinala a relação entre o seu peso (quantidade) e a sua expansão (qualidade).

Isso nos sugere as linhas-força que caracterizam o objeto e nos levam a uma unidade que é a interpretação essencial do objeto, isto é, a intuição da vida. A nossa é uma pesquisa do definitivo na sucessão dos estados de intuição.

Recusar uma realidade a priori, eis o abismo que nos separa do Cubismo, o que faz de nós futuristas a ponta extrema da pintura mundial. Na Itália, nós somos os primeiros artistas que se preocupam em dar à sua arte aquilo que sempre foi o caráter da arte italiana nos seus melhores períodos: estilo e realidade.

Recebido para publicação em 06 de julho de 2008.

Aceito para publicação em 28 de setembro de 2008. 